\title{
WHY ART?
}

DONALD ALGEO

1 .

Consider the case of the viennese artist, Rudolf schwarzkogler. Sometime during the first years of the decade, Schwarzkogler, in an unsettling variation of body art, undertook to amputate, inch by inch, his penis, while a photographer recorded the successive stages of the action. In 1972, the resulting prints were displayed in a show, "Documenta 5," at Kassel. Schwarzkogler's active influence of other artists (e.g. Hermann Nitsch, Chris Burdon), has been written about in art books, and so on. Was it therefore art?

lt is not its shock value which makes me wonder--to the sensibilities of the seventies, Schwarzkogler's action may seem no more outrageous than was, say, "Le Dejeuner sur l'Herbe" to those who first viewed it or heard about it: Nor is it merely the eccentricity of the act--even though artistic bohemianism is on the wane, artistic eccentricity will (one prays) always flourish. My doubts about it are of a different sort.

Les Levine, among the most radical of the Idea Artists, has said of schwarzkogler, "He called it art, but we don't have to call it art." 1 His point is not that Schwarzkogler was not an artist, but that he was a mad artist, who madly damaged the cause of Idea Art. The cause of Idea Art was to expand the possibilities of art, not (as is often claimed, both in assault upon the defence of the movement) to sever art from its history. 
Now consider a quotation from Arthur Danto:

The relationship between reality and art has traditionally been the province of philosophy, since the latter is analytically concerned with relations between the world and its representations, the space between representation and life. By bringing within itself what it had been traditionally regarded as logically apart from, art transforms itself into philosophy, in effect. The distinction between philosophy of art and grt itself is no longer tenable.

But this would be true only if disciplines (e.g. philosophy) were defined solely by their subject matter, and they are not. That artists have lately become interested in something which previously interested, in the main, only philosophers does not make them philosophers, any more than philosophers become scientists when they begin to speculate upon the nature of perception.

It is one of those "borderline" problems. Poets are often wise, and often adept at conveying wisdom; but not every means of conveying wisdom is philosophical and we know that to be so (or at least strongly suspect it) even though we may not yet be able to say precisely what poetry or philosophy is. Painters may have insightful, profound, or witty things to say about a variety of subjects, and they may say them in a variety of ways, but that does not necessarily make them philosophers, nor the things they have to say philosophical. Or again, philosophers may have trenchant things to say about art, but that does not make even what they say necessarily philosophical, for philosophy is not a form of mind control, and even philosophers are free to say something nonphilosophically profound.

By exactly the same reasoning, artisț may have a great deal to say about art, much of it very acute, but that does not guarantee that what they have to say is either philosophical or artistic. As a philosopher may play golf on the weekend without destroying the distinction between golf and philosophy, just so an artist may amputate his penis without destroying the 
distinction, admittedly a fine one, between madness and art.

3.

George Dickie has been arguing for some time in favor of what he calls "an institutional theory of art." Its most recent formulation is:

[a] work of art in the artifact (2) a set of the aspects of which has had conferred upon it the status of candidate for appreciation by some person or persons acting on behalf of a certain 3 social institution (the artworld).

The most troubling elements of this theory are, first, who it is who counts as a member of "the artworld," and second, what it means to confer upon something the status of a "candidate for appreciation." Both of these questions have been raised by Ted cohen. In wondering if it is as obvious as Dickie claims that Duchamp's displayed urinal, "Fountain," is a work of art, Cohen asks: ". . . in what circumstances and by whom can this property [of being art] be bestowed, and what qualifies a thing to recieve this bestowal?"

With respect to the first question, Cohen wonders whether "Fountain"'s being art, if it is art, might not be due to its having been displayed by Duchamp, i.e., by someone who had already gained a certain status in, had been enfranchised by, the artworld, as a result of his earlier production of more conventional artworks. That having attained some sort of status in the artworld is necessary for legitimately presenting something as a candidate for appreciation seemed to have been both implied and denied by Dickie's remarks. It had been implied by an analogy which Dickie of fered between Duchamp's offering something as a candidate for appreciation and a head of an election board declaring someone a candidate for alderman (since only someone duly enfranchised by appropriate authority can meanfully declare someone a candidate for alderman). It had been denied by Dickie's remarks to the effect that, e.g., a plumbing salesman, rather than Duchamp, might (presumably while remaining a plumbing salesman, at least to the extent of not having "gained status" by producing preliminary works of art) have conferred the appropriate status upon the urinal. 
In reply, Dickie contended that these two analogies were ampliative rather than incompatible. For him, the sense in which the plumbing salesman could have made art out of a urinal is the sense in which he could have, if it had occurred to him to do so: "The salesman could do what Duchamp did, that is, convert a urinal into a work of ${ }_{6}$ art, but such a thing probably would not occur to him".

One's conservative inclination is to shrink from this claim, since it seems to imply that having the thought occur to someone to make something into a work of art is all that is required to have the appropriate status in the artworld. Surely, one is tempted to say, surely more is required--perhaps the cooperation of museum directors, of art patrons, of someone whose position in the artworld is a little more secure or elevated.

But no; Dickie seems intent upon extending his liberality to the limit:

The institutional theory of art may sound like saying, "A work of art is an object of which someone has said, 'I christen this object a work of art. $_{7}$ " And it is rather like that.

And, despite Dickie's immediate qualification of the above remark--". . . although this does not mean that the conferring of the status of art is a simple matter"--the general drift of his argument makes it appear a very simple matter indeed, requiring only the uttering of a short formula by someone (and here "someone" is clearly meant to be synonomous with "anyone") who understands what he is saying. This is, of course, not to deny that it is a complicated cultural matter to produce a linguistic comnunity comprised of people, most of whom are capable of significantly saying, "I christen this object a work of art." It is only to say that, given the existence of such a community, there is, seemingly, in Dickie's view, nothing easier than producing art. Any child (plumbing salesman, normal speaker) could do it.

Perhaps so, but let us go on. With respect to the second question, Cohen wondered whether there might not be certain things which are not qulaified to receive the bestowed status of art, and he believed that Dickie's very definition suggested the class of such things. Since Dickie required that art objects have 
been offered as candidates for appreciation, it follows straightaway that just as nothing can be a promise which cannot (for whatever conceptual reason) be accepted, nothing can be offered as a candidate for appreciation which cannot be appreciated (or at least of which it is thought that it cannot be appreciated). If, then, there is anything of which it is thought that it cannot be appreciated, that thing cannot be a work of art.

Are there such things? The answer will depend upon what is meant by "appreciation." Dickie allows the notion considerable rein, so that one can be said to appreciate something if "in experiencing the qualities of [the] thing one finds them worthy or valuable."

Generous as this definition is, certain things, Cohen suspected, probably still escape it, and he cited thumbtacks, cheap envelopes, plastic forks, and, intriguingly, "Fountain," as examples. His doubts about the first three sorts of things are obvious enough: they are, after all, so ordinary and dull. The case of "Fountain" is more complex. What is noteworthy about "Fountain," if anything is, is that it was selected, as were many works of Dada, by its advocate precisely because of its apparent lack of appreciable qualities. Cohen quotes Michael Fried expressing anxiety about whether Dada had wrenched art too far away from its traditional concern with appreciation, but he might more disturbingly have quoted the artist himself; speaking of his "Readymades," ordinary objects supposedly converted into art simply by indexing them as such, Duchamp said:
A point I want very much to establish is that the choice of these Readymades was never dictated by aesthetic delectation. The choice was based on a reaction of visual indifference with $\mathrm{a}_{9}$ total

Dickie's reply to this sort of counterexample seemed completely to miss the point. Anything, he appears to have said, has some quality or qualities which can be appreciated. Even "Eountain" "has many qualities which can be appreciated--its gleaming white surface, for example."

Maybe so, though Duchamp might no doubt have remedied that particular oversight--by being less fastidious in his choice of urinals, perhaps. But this 
is silly. Any self-respecting Dadaist would have taken Dickie's remark as a challenge, and gone hurrying off in search of something which no one could appreciate, in any sense of "appreciate" narrower than the one in which it means simply "perceive."

The point is obvious. Robert Barry once had an exhibition in a gallery in which nothing was displayed, the door was locked, and the only evidence that an artist was even involved was a sign hung outside the door which read: "For the exhibition the gallery will be closed." What is being offered as a candidate for appreciation here? The sign? Should we carefully inspect it for qualities which we find worthy or valuable? Its texture, perhaps? The neat lettering?

The point is exactly what Cohen said it was: what the Dadaists (and, more recently and forcefully, such groups as minimal artists, body artists, conceptual artists) were offering were not objects for appreciation, but rather, at least sometimes, remarks, theories, even jokes about art. Their point, and it is not very far at all from Dickie's, is that anything, even nothing, can be accorded the status of being art, and not by so avuncular a means as offering it as a candidate for anyone's appreciation either, but simply: Presto! Chango! The artist as magician.

4.

So here is the situation. Dickie wants us to accept "Fountain" as, obviously, a piece of art, but for reasons which Duchamp himself would resist. It would seem that, in the fact of this difficulty, Dickie has only two alternatives. Either he might say that the notion of "appreciation" he is invoking is liberal enough to accommodate varieties of "finding worthy or valuable," other than "finding the sensible qualities in themselves worthy or valuable" e.g., finding the theory or remark or joke symbolically expressed worthwhile or valuable to reflect upon. Or, he might deny that "Fountain" is art.

Let us assume that he would not do the latter. If he did the former, then his view would be the same as Danto's. For, if the only appreciable qualities of "Fountain" are, say, the attractiveness and importance of the theory about art which it symbolizes or adumbrates, and if it is nonetheless art, then, indeed, the distinction between art and philosophy has collapsed. 
Concepts change, there is no denying that. And perhaps the concepts of art and philosophy might change (have they already?) in such ways as to collapse the distinction between them. That would have happened, I suppose, whenever it had come about that everything which was called "art" was produced only in order to make or illustrate a point about something and examined only in order to discover and assess that point. That could happen; it has obviously happened already with respect to quite a few things which currently are called "art."

But are there reasons for retaining, or at least encouraging the retainment of, the distinction? I think so, and I will attempt to say what these reasons are in the remainder of this paper.

5.

Paul ziff is clearly right in pointing out that it is an important matter whether something is considered to be a work of art or not, because of "the characteristic social consequences and implications"I of doing so. In western society, ziff notes, such consequences include that a work so considered is likely to find its way into a public museum, to have public funds spent on it, to be read about and studied by the public.

Ziff is careful not to restrict the possibilities for such consequences or implications, noting that "they have, varied in time, and no doubt will continue to do so."I2 His caution is justifiable, for the relativist might point to the fact that it was once a characteristic implication of something's being considered a work of art that it be buried away with its expired owner, talismanically to aid him or her with the complications of the netherworld. Or she might point to another time and place, where it was such a consequence that the artist have his fingers lopped off prior to execution, all of this before a - stadium filled with political prisoners. 3 or, finally, she might point to some possible future time, when the consequences might be whatever you please, perhaps even that the thing in question be avoided or ignored as anathema or danger to some perverse worldview or another.

still, despite this variety, both actually past and futurally possible, I think it is worthwhile to draw attention to one particular consequence which has been 
characteristic of something's being considered to be art throughout the western tradition, and throughout the non-western traditions as well, so far as I know. That is that there has always been a tendency to contemplate closely in the mode or modes appropriate to the medium or media anything which has been considered to be art. There has been a tendency to listen carefully to music, to scrutinize paintings intensely, to exercise imagination vigorously in reading works of fiction. And other artforms-oral poetry, opera, movies-have, of course, elicited more complex structural modes of close contemplation.

Why is it important to draw attention to this hopefully non-controversial fact? Because it suggests strongly that, amidst whatever surroundings, art has served some abiding function, has met some deep-seated human need.

What that need (or needs) might be is a matter for discussion, and it is a discussion which for over two thousand years preoccupied philosophers concerned with art, though it has not sparked much interest in the established Anglo-American tradition for some considerable time. I shall have some suggestions to make about it in section 10 .

But for the moment, although we leave it nameless, let us suppose that there is at least one such thing, that art has long persisted in response to some human demand, however clearly felt or explicitly articulated, that it exist. What would follow from that in terms of the question at hand, viz., whether and to what the appellation "art" should be restricted?

What would follow depends upon determination of the following matters:

1) whether that unnamed need is one which we ought to continue to meet; and

2) whether restricting the use of "art" in some manner, with all the predictable consequences of so doing, would be a singularly good way of accomplishing that aim.

Suppose that both of these questions were answered in the affirmative; then we would have good reason, other things being equal, to encourage such 
restriction, and to resist certain efforts at expansion (although not all expansion in every direction).

For example, we might have good reason--and I stress might, for there are a number of complications-to excise "Fountain," "Documenta 5," Robert Barry's empty gallery, and a goodly number of others from the realm of art. It is that possibility which 1 will now explore, and I will do so by the methodologically odd device of first giving and elaborating upon my suggestion for what the restriction should be, before returning, in section 10 , to the very difficult matter of providing the justification for that restriction. The reasons for taking this roundabout route will be clear by the time we reach that section, and I will also return there to the two matters for consideration mentioned above.

6.

My suggestion is that it be required, as a necessary condition for something's being considered to be art, that it have been produced by an artist with the intention, in large part, of creating something of aesthetic value.

This requirement may sound a little naive, but I think that, on inspection, it will prove not to be naive at all, but instead very sensible. Let me try to establish this by examining its three obviously contentious elements, viz., its reliance upon the thing's having been created by an artist, its reference to the artist's intentions, and its invocation of the notion of aesthetic value.

7.

What prompts me to require of art that it be produced by an artist is a certain degree of discomfort which I feel upon reading such things as the following:

[In the artworld we] would expect to see . . . Beethoven symphonies, Irish folk songs, short but interesting compositions by a five year old named Mozart, we would expect Paradise Lost, love sonnets, lines of verse written by a ghetto child on an alley wall; we would 
expect marbles depicting mythological figures, wires dangling from a ceiling, Brillo boxes, welded configurations of scrap iron, a papier-mache model made in Miss Kunst's tenth grade art class. 18ne

Must one expect to see these things in the artworld? Why must one? If one must see them all as members, may one nonetheless distinguish between them in terms of their credentials?

There are two ways in which one's membership in an institution may be, so to say, unelevated. On the one hand, one may be a full-fledged but uninfluential member: a novice in the priesthood, cub in the Boy Scouts, private in the army. On the other hand, one's membership may be less than full-fledged: one might be an honorary member, a provisional member, or an apprentice.

If I must look upon a child's graffiti as art, or papier-mache models in a tenth grade art class, or, carrying this sort of reasoning to its hilt, the doodles my colleague incessently concocts at boring lectures, may not I at least see them as less than full-fledged art? Why exactly must I provide a theory which accords them unconditional, though unelevated, membership?

Suppose the child scribbles, not a rhyme, but rather, "I drink, therefore I'm a man." If I am trying to say what philosophy is, must I be careful to couch what I say in such terms as to ensure that this protophilosophical remark has full status in the philosophy-world? Must anything which bears any relation to obviously full-fledged members of a particular $x$-world themselves be full-fledged members? Suppose the child had written, "I am equal to you." Must we define mathematics in such a way as to ensure that this is a full-fledged member of the mathematics world?

But what about these short pieces of the five-yearold Mozart? Surely they are art, and if they are art, then the crude productions of all five-year-old children, whether on the piano or on ghetto walls, must also be art.

Yes, these early Mozarts probably are art; but need it therefore be true that anything which bears some 
resemblance to them, however remote, is art? When my five-year-old child dribbles her fists across the keyboard, are her productions necessarily also art? But then, by the same reasoning, the trills of songbirds are art.

I suspect that the assumption upon which this sort of demand rests is one which has it that art must be thought of in the same way in which we think of, e.g., determinate symbols, things like words. Let me explain by offering a consideration which will also be relevant to the following section.

Suppose I walk into a classroom and see a strange mark on the blackboard--suppose it is this mark: ' 7 . I am about to erase it when one of my students--a budding Arabic scholar--offers the information that it is the Arabic word for "plum." We conjecture for a few minutes about how it might have gotten there, whether it was written by someone who knew what it meant or whether, just by coincidence, someone lappened to scribble something which was this word. We cannot decide, so I erase the board, and the class begins. What is to be noted about ' $\%$, and this is always true of such symbols, is that they are symbolic, whatever the intentions of the person who produces them, or even whether they are produced by anyone at all--a cloud formation of the number seven is an instance of the nuinber seven.

Suppose it were necessary to think of art in this way: It would follow that it is unnecessary to determine whether a thing was created by someone, and to ask after his intentions in doing so, to see whether it was art. And we would then have reason to speculate about what the relevant conventions are for something's being art--and perhaps we would decide, with Dickie, that they were certain conventions of the contemporaneous artworld.

But it is not necessary--I also want to say, not even best--to think of art in this way. We may instead think of it in the way in which we think of purposeful symbolic constructions, e.g. messages. If I discover this mark on the board: ' $\rho$ ', and $I$ learn that it is Arabic for "Help!," I still don't know whether I've discovered a message or not. To know that, I would have to know that someone put it there with a certain intention.

similarly, that my child's hammering bears a close resemblance to certain modern pieces of music is no 
proof positive that it is art, any more than the resemblance of the wind through the willows to soft violins makes it art. At least one thing more which is needed, I suggest, is the participation of an artist.

What makes someone an artist? surely not merely that he produces something which bears a resemblance to archetypal cases of art. If that were true, then housepainters would be artists. But if that is false, then there is no reason to insist that the students in Miss Kunst's tenth grade class are artists, or that my frolicsome child is an artist, or the ghetto child.

What makes someone an artist? Being an artist is not like being a Caucasian or a male. Artisthood is a role, like philosopherhood--but not like parenthood or priesthood. It is something which one can step into and out of in a flash: that is why philosophers can also act as artists, and artists as philosophers.

To have taken on the role of an artist is not to have taken a profession, though of course there is a profession occupied by those who have made this role their main professional role in $1 \mathrm{ife}$.

How could a philosopher (or a secretary, or a nurse) act as an artist? By having understood what it is to engage in a certain intentional activity, and by intentionally engaging in that activity.

Why isn't the person who accidentally scrawls ' $f$ ' on the blackboard sending a message? Because he didn't see that point in what he was doing as he watched the figure emerge in front of his thoughtless hand. Why isn't what my child bangs out on the piano art? Because she is only trying to make noise, to occupy time, to annoy her father.

Why is what Mozart produced art? Because he (precociously) intended to create something of aesthetic value.

Why is it that what Schwarzkogler did was (probably) not art? Because he was (probably) simply insane. Because we must strongly suspect (though here is a case in which we shall never know, and nor does it matter) that his intentions had become unraveled and alien, in the way of the mad. 
My formulation clearly contains a redundancy. In it, I require that the producer of the object be an artist--be acting as an artist--and acting as an artist, I have said, only means acting with a certain intention. I might, therefore, simply have said that art is whatever is created with, in large part, a certain intention. There is that redundancy, but, since redundancy is not logically pernicious, I cloose to allow it because it enables me to focus upon this supposed problem of doodles, scrawls, and crude papiermache molds with no danger of that discussion's being interrupted by a completely different problem concerning intentions with which it is sometimes confusingly conflated. Let me now turn to this problem, and leave it to the reader's discretion whether he wishes to whittle the formulation down to its barest bones.

There is a kind of objection which is very commonly made against views which rely, as this one does, upon intentions. The objection runs somewhat as follows: If this view were correct, then we could not know if something was an example of art unless we knew what the intentions of the person who produced it were at the time. But that is absurd. For obviously we can know that e.g., Marlowe's Faustus is a work of art, even though there is no means of determining what Marlowe's intentions were when he produced it. And similarly for Grecian urns, African masks, neolithic cave paintings, and so on, where, first, we don't even know who the producers were, and second, we have good reason to think that, whoever they were, their intentions were, in the main, other than the ones required by this view for art.

There are two sorts of mistakes involved in offering these two types of supposed counterexamples.

To the second type, the correct reply to make is simply that what is at issue is whether Grecian urns, cave paintings, and so on, are examples of art. It will not do to say that obviously they are, since they are written about in art textbooks, exhibited in art museums, and such like. The person who supports the view under attack here is precisely the one who denies that these are decisive criteria for determining whether something is art.

The first sort of counterexample is different, for no one would seriously deny that Faustus is a work of

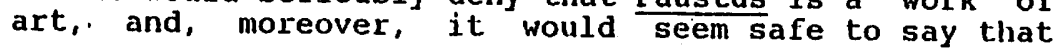


Marlowe's intentions in producing it are lost in the past, never to be recovered.

But is that true? Are Marlowe's intentions really lost in the past? What would lead anyone to say that, aside from the most arid kind of epistemological skepticism? We have as good a sign as could possibly be required of what some of Marlowe's intentions were in writing Faustus, a sign at least as good as any contemporaneous first-person report would have been. That sign is, of course, Faustus. I can say, with as much confidence as our existential isolation allows, that Marlowe intended to create something of beauty to delight and entertain an audience. of course, it is conceivable that he had no such intention, that his sole intention was (say) to enable himself to pay off his debts. It is also conceivable that he wrote it in his sleep, or that it was not written by Marlowe at al1, but instead came into existence by some remarkable machination only yesterday, all copies of it, along with all commentaries on it and all our reflective associations about it. Any of these is conceivable, but let us not philosophize in that vacuum.

And now, returning to the other sort of counterexample, we can see that the view under consideration is really not so disruptive as it might have seemed. I, for one, am not the least uncomfortable in saying that Greek vase paintings show evidence of considerable aesthetic concern; in fact, I cannot quite imagine what sort of possibility someone who denied this would be relying upon: that the symmetry, evocative power, and narrative urgency of these beautiful things might be mere happenstance? And similarly for the heroic grace and regal coloration of African warmasks, the fine, dizzying balances of Persian carpets, the witty elegance of certain Chippendales.

Cave paintings, I suppose, largely inhabit the border areas: the Altamira standing Bison and the painted hunters from Cueva del Civil clearly reflect aesthetic concern; the engravings from Bohuslan probably do not. These latter are difficult cases, but not in the sense of cases which pose difficulties for the theory. On the contrary, it seems to me a mark in favor of the theory that it allows for exploration and hypothesis about a certain range of cases. To reiterate one of Cohen's concerns, it is a troubling aspect of alternative theories that they make the question of what is art naively easy. 
9.

We come now to the question of aesthetic value and, in so doing, we pick up again on the issues raised in section 5 .

The logical problem posed by the reguirement I have suggested is clearly one of avoiding circularity, of avoiding defining "aesthetic value" in some way such as, "the value attaching to works of art." such a claim would be bootless, amounting, in effect, to saying that art must be created by someone with the intention, in large part, of creating art.

This logical problem is fairly immomentous, for the history of aesthetics offers us plentiful candidates for such uncompromised value: Kant's Gemeingueldigkeit between the faculties of understanding and imagination is one example; Dewey's communication through objective form of emotional meaning is another; Tolstoy's communication of emotion a third. The real problem, if one is seeking to understand the phenomenon of art by reading the great aestheticians, is to assess these views according to other criteria: coherence, consistency, intelligibility, phenomenological adequacy, etc.

I will not do that here. Instead, I will draw attention to a value so steadily associated with what have always been conceded to be artworks, while being so unportentous, that it may serve as a hallmark of art's presence without presupposing, say, elaborate metaphysical commitments (Kant), or a complicated theory of meaning (Dewey), or a dubious epistemology (Tolstoy).

I said earlier that one characteristic consequence of something's being considered to be art that has persevered through the colorful history of such consequences is that an object so considered is likely to be the subject of close contemplation on the part of some public in the mode appropriate to the medium of the object. I now propose that the reason for the persistance of this characteristic consequence is that art, throughout the ages, has served always the function of educating its audience to see, to hear, to imagine, and to feel, and that these faculties yearn for development as avidiy as the stomach does for food.

There is no single term which is perfectly suited to name the genus for the various species of development I have in mind. "To feel" leans away from 
sight and sound; "to perceive" and "to experience" are both too occurrent and object-bound. "To sense" is scarcely better, but it does have the considerable advantage of a cognate in the nominative case, as when we speak of someone's sense of balance, or sense of color and line, which well accords with certain points I want to make about the value in question. Accordingly, I will speak generally of art's capacity to teach its audience to sense, leaving it to the ensuing remarks to clarify the usage.

Let me give an example of the sort of educative process I have in mind. We find a clue to the realm of clearest examples in the wel1-worn phrase, "a sense of taste," which serves to applaud sophistication in all other realms. Let us talk of cookery.

What is it for a palate to develop? It is two things, or rather, two aspects of the same thing. On the one hand, it is to acquire intimacy with the indefinite complexity of the world of food. As faces and personalities gradually take shape out of an anonymous background for a stranger in a community, so the many inhabitants of the food world acquire recognizable character for the explorer in its regions. What was once one mustard suddenly becomes two, and then three, and one is astounded at having failed hitherto to distinguish them. We may speak of this as the education of the palate.

On the other hand, to develop a palate is to develop a discrimination; it is to be able to judge new taste sensations, both as to their category and their quality. Hume long ago made the point elegantly enough to free the rest of us for other reflections. In matters of sensuous discernment, the judgments to be trusted are those issuing from authority gained through long and serious study. Nowhere is this clearer than in eating. To the standard objection that even experts sometimes disagree, the proper reply is to point to the remarkable concurrence of opinion, against which the occasional spat (oftentimes more politically than aesthetically motivated) shrinks almost to nil in significance. To the other usual objection, both more sophisticated and more disingenuous, that the claim is circular because it defines what is good as what is pronounced to be so by those qualified to judge, and then names the relevant qualification as the ability to recognize what is good, there is also an easy reply. For that is not what the qualification amounts to; rather, one is qualified to pronounce on such matters 
once one has gone through a period of long and close study of the subject matter. It just happens to be the case, as a contingency, that there is such remarkable concurrence among the qualified groups as to what is to be preferred. It is not a part of the definition of that group that there be that concurrence, but that there is supports rather than undermines the central claim.

So, we will take it as established that discrimination in taste grows with practice.

It happens that there is a class of people, subsidized in various ways, whose professional dedication to culinary concerns has paved the way for more general palate development. I name only a few from that honor roll: Careme, Escoffier, Soule. Through their schools, their showplaces, and their publications, they all contributed to the refinement. both in education and discrimination, of the palates of those fortunate enough to have had access to them.

Is that spreading effect a good thing or not? We will come back to that question, but first, let us look at an activity more universally considered to be at the center of art.

For purposes of space, I will limit my remarks to painting. I believe that if the sort of claim I wish to make is plausible with respect to painting, it will also, mutatis mutandis, be plausible with respect to literature, music, dance, architecture, sculpture, and the combinations of these in more complex genres.

Painting is a mode of activity which lends itself, in the first place, to visual address; the medium for whatever further accomplishments paintings may achieve consists entirely of an assortment of pigments, whose smells rapidly disappear after they have dried, leaving only color and line and texture for appreciation.

What have painters accomplished with their pigments? An enormous variety of things, of course. They have found in paint the possibility for representation, illusion, conveyance of impression, emotional expression, and so on.

But there is one accomplishment, 1 suggest, which has run through these others like a thread through variegated beads. What $I$ have in mind is this: throughout its history, painting has refined the sight of its audience. 
Taking our direction from the remarks about cookery, we may divide this refinement into elements of education and discrimination. Thus, one function which painting has served is to show its audience what the artist saw, to present to the audience the fine detail, articulation, and intensity of the visual or imaginative scene available without mediation to the artist. Just as cookery has educated people to the subtlety of the gustatory world available to the palate, so painting has educated people to the subtleties available to the eye. No one [who has pursued a serious course of study of the development and greatest examples of landscape painting can fail to appreciate the available qualities of a landscape with greater refinement than before. The variations on a basic common theme, wooded hillside, say, hovering over water; the community of theme itself; the astonishing ways in which nature achieves its visual effects: these and many, many other qualities become vastly easier of access to the eye trained in their appreciation. similarly, the human face and form become donors of much richer and more multifarious detail to the eye educated in their perusal by the masters of figure study and portraiture. And who had ever contemplated old shoes with much attention and interest, before Van Gogh turned our undivided visual attention to a particularly dilapidated pair? And who, having given "shoes of a Peasant" close study, can fail to look down and see his or her own in a new light?

Nor is this any the less true of art which repudiates illusion, as Van Gogh's painting already begins to show. Even at its most abstract extremes, painting serves that function. Rothko's monochromes educated our eyes to the expressive properties of, e.g., various hues of gray. Why are overcast days gloomy? In part because gray, in certain tonalities and certain contexts, just is expressively gloomy. I look out of the window of my office. Directly below, the parking lot has been repaved over the summer, and it is a very dark gray. Beyond it, the lighter gray of the older asphalt road cuts across. The road looks distant, impersonal, a little threatening. It would not have looked so to me before I began looking closely at Rothko's work, any more than one kind of mustard would have tasted slightly more piquant to me than another before $I$ was educated to their difference. Similarly, the dancing yellow and red and blue squares in Mondrian's "Broadway Boogie Woogie" teach one to see the expressive possibilities of yellow and red and blue, perhaps for the first time, certainly more keenly than one did before. And in the same vein, Cubism gave 
us lessons in the shifting geometrical understructure of the world, Futurism in the complex dynamics of that shifting, and so on.

And just as the palate's refinement leads through education to discrimination, so the educated eye becomes an eye capable of, usually eager for, further unassisted exploration. Not all natural motifs have had the attention of painters, probably not even a large fraction, but the eye schooled in those which have been treated finds itself in time a fit critic of those which have not. Once attuned to the expressive properties of flat expanses of certain colors, once trained in their inspection, other colors begin to beckon. The Italian Futurist, Giorgio de chirico, made the same point with great force speaking of one of his own paintings:

Sometimes the horizon is defined by a wall behind which rises the noise of a disappearing train. The whole nostalgia of the infinite experience the most unforgettable movements when certain aspects of the world, whose existence we completely ignore, suddenly confront us with the revelation of mysteries lying all the time within our reach and which we cannot see because we are too short-sighted, and cannot feel because our senses are inadequately developed. Their dead voices speak to us from near-by, but they spund like voices from another planet.

Suppose this is true; is it important? Again, I delay addressing this guestion, this time in order to make two points.

First, it is the farthest thing from my mind that art either has in the past or should continue to have this educative function as its only task and promise. What painters, to stay with them, can accomplish through their medium is limited only by their individual and communal genius, by their history, and by the climate of their times, not by anything I have suggested. That "Guernica" has been of greater moral moment than most ethical treatises written in this century is sufficient testimony to the almost miraculous possibilities of paint. 
Second, I have limited my proposal to providing only a necessary condition for something's being considered to be art for the following reasons: a) because I think that merely requiring it of art, without running the theoretical risks of over-extension which sufficiency conditions always bring in their wake, would be of adequate consequence to achieve the desirable. end which I shall discuss in the next section; and b) to qualify the proposal in such a way as to make it adequate to serve as a statement of both necessary and sufficient conditions would require more space than presently available. Let me, however, before proceeding to the final stage of the argument, just gesture in the direction in which such a development, in my view, should proceed.

There are three things, I would argue, which are especially characteristic of the artist's methods of teaching to sense. First, they are highly skilled; second, they are elaborate; and third, they proceed through a process which I call ostension, a kind of pointing.

Thus, the practice of art has historically followed upon a period of training designed to develop and hone the relevant skills of the individuals concerned. Except for the freakish few, almost all of them musicians, whom nature gifts prodigiously and without prior payment, the history of art is a history of ice tips above mountains of labor and routine.

"Elaborate" I use as a term covering features both internal and external to the artwork. A piece may be elaborate by being internally complex, or by being situated in and referred to the relevant context. So, for instance, Rothko's monochromes satisfied the elaborateness condition by virtue of their placement over against the preceding history of abstract expressionism. In a literal sense, the works of the other participants of that history surround Rothko's works just as responsively and responsibly as the dark brooding spaces of Rembrandt surround the nervous people in his portraits.

When I say that art works through ostension, or that it ostends, I am referring to the way in which a painting, say, proceeds by gathering the attention to itself and directing it from point to point, from region to region, or even (as in Rothko's case)' beyond itself to other paintings. Painting does not tell you how the world looks; it shows you. And so also for literature, although not so obviously. I have, to 
repeat, for reasons of space not brought the analysis of this paper to other genres, but here it would be well to note how literature educates the imagination and, consequently, the emotions. It is by creating a world, enticing the reader into it, situating the reader in a precise place in that world, and letting his or her natural powers of sympathy operate in that exact context. What are the varieties of pity and shame that one person can feel for another? Read the Dubliners and Joyce will educate you in dozens of them, not by telling you what they are-who ever learned to feel in a new way by hearing about it? but by involving you in the exactly appropriate setting and letting you feel it for yourself.

These last remarks are both contentious and murky, I know. But I do think that, if the final stage of the argument coming up has any weight, then a very strong case could be made for stipulating, as a necessary and sufficient condition for something's being considered to be art, that it have been created by an artist with the intention, in large part, of creating something capable of educating its audience to sense through skillful, elaborate ostension. If the reader is at all persuaded by the concluding claim that there is good reason for accepting my necessary condition, then he or she should begin to see that there would be an a fortiori better reason for accepting the necessary and sufficient conditions. But I leave the working out of that claim to another time.

10.

We are now at the final stage, and we ask for the last time: suppose this is true, is it important? specifically, is it important that art be encouraged to continue serving this function, even at the expense of deflecting it to some degree from other functions, the philosophical, for instance, which it might wish to pursue?

I think it is very important that art maintain this hold on its past, or, if you prefer, that its past maintain this hold on art. There are a number of reasons why it is important, the simplest being that it is just a good thing that highly trained teachers are available in these matters: the development and exercise of the senses is one of the fundamentally good things (one is tempted to say, with Moore. intrinsically good things) which human beings, constantly busy and beleagured, have chanced upon 
during their turbulent history by some amazing good fortune.

That alone would be sufficient, I am convinced, to justify encouraging any reasonable steps which would make more likely the continued existence of a class of people who are especially skilled in the promulgation of this good, and at leisure to do so. But I think that the danger of allowing or encouraging artists to drift farther and farther from their sensible media is even greater than this remark would indicate. For it is not only a considerable good which would be diminished with such drifting, but also the resistence to a considerable evil--and that is what is so deeply worrisome.

One need not be of any particular political affliliation to realize that one of the, if not the, major dramas being enacted in modern industrialized societies is that concerning technology. It is a drama whose antagonists are technology under control and technology out of control, technology developing under reasoned moral guidance or developing according to its own internal impetus.

I do not feel I need to argue, nor could I possibly do so in this space, that technology out of control would be a very, very bad thing. Heidegger, for one, has spoken to the issue with great sophistication in The Question Concerning Technology, and I refer the reader to that essay. So I shall simply assume that it would be a bad thing, and make one last claim based upon that assumption, a claim which will bring this paper to its close.

My claim is that the developed ability to sense is one of the major obstacles in the way of technology growing out of control. If that is so, then an extemely strong prima facie case will have been established for taking reasonable steps to safegaurd and further develop that ability.

Is it so? I cannot prove that it is so; it is not the sort of claim that admits of proof. But I hope I can recommend it to your serious reflection by the following remarks.

No one, I suggest, [who had studied closely Rembrandt's human beings, or who had learned to feel with Joyce's haunted human souls] could continue to speak blithely, and without ever having reflected on what he or she was saying, about human resources. No 
one [who had learned under Constable's guidance how to look at landscapes] could see a wooded hillside hovering over a lake merely as--to use Heidegger's term--standing reserve (a sort of energy reservoir). And no one could step out of the house in the morning and encounter the world with utter alienation and hopelessness after being taught by Rothko, Pollock, Mondrian, klee, and picasso that the world is constantly addressing itself, with undemanding beneficence and goodwill, to him or to her.

The dehumanization of human beings, and the loss of wonder at the world--these are the handmaidens of technological progress, threatening always to clothe her completely according to their taste. Art, I suggest, perhaps preeminently, stands in their way.

It should be a necessary condition for something's being considered to be art that it have been created by an artist with the intention, in large part, of creating something with the capacity for teaching its audience to sense. Should that proposal be generally accepted, we should have taken a significant step, given the characteristic social conseguences of something's being considered to be a work of art, towards ensuring the existence of classes of people especially gifted and trained in the desired skills. The existence of such classes is in turn justified by the intrinsic good of its productivity, and by the evil threatened by its disappearance. That is the argument. But the point is, the way to the spirit is through ${ }_{17}$ the senses, and it is human spirit which is in danger. 


\section{NO'TES}

${ }^{1}$ Les Levine, "Two Views on Advanced Art," in Idea Art, ed. Gregory Battock (New York: E. P. Dut ton, 1973), 198. Actually, Levine's remarks are open to several interpretations, so I am perhaps unfairly attributing to him this attitude towards schwarzkogler, although I don't think I am.

2 Arthur Danto, "Artworks and real things," Theoria, XXXIX (1973), 17.

${ }^{3}$ George Dickie, Art and the Aesthetic: and Institutional Analysis, (Ithaca: Corneli University Press, 1974), 34. This definition is a reworking of an earlier, less satisfactory formulation. Cf. Dickie, "Defining Art," American Philosophical Quarterly, VI (July, 1969), 254.

${ }^{4}$ Ted Cohen, "The Possibility of Art: Remarks on a Proposal by Dickie," Philosophical Review, LXXXII (1973), 72 .

${ }^{5}$ Dickie, "Defining Art," 254-55.

6ickie, Art and the Aesthetic, 38 .

${ }^{7}$ Dickie, Art and the Aesthetic, 49.

${ }^{8}$ Dickie, Art and the Aesthetic, 40-41.

9 Anne d'Harnoncourt and Kynaston McShine (eds.), Marcel Duchamp (New York and philadelphia: Museum of Modern Art and Philadelphia Museum of Art, 1973), 89.

${ }^{10}$ George Dickie, "The Actuality of Art: Remarks on Criticisms of Cohen," The Personalist (Apri1, 1977), 171. 
${ }^{11}$ Paul Ziff, "The Task of Defining a Work of Art," in Philosophic Turnings, (Ithaca: Cornell University Press, 1966), 39 .

\section{2 ziff, 44-45.}

13 As happened recently to the chilean folksinger, Victor Jara.

${ }^{14} \mathrm{R}$. J. Sclafani, "Artworks, Art Theory, and the Artworld," Theoria, XXX1X (1973), 23.

${ }^{15}$ Quoted in Herbert Read, A Concise History of Modern Painting, (New York: Frèderick A Praeger, 1959), pp. 121-22.

16 Martin Heidegger, "The Question Concerning Technology," in The Question Concerning Technology and Other Essays, (New York: Harper and Row, 1977).

${ }^{17}$ I wish to thank Cyrus Banning, Daniel Kading, Ronald McLaren, Thomas Short, and the referees of this journal for their helpful criticisms and suggestions. 